\title{
Journal of Regenerative Science: A Step towards a more Biological Future
}

\section{Ashok Shyam ${ }^{1}$}

Biology defines and forms basis of every disease and treatment modality, it is the fundamental on which the entire science of medicine stands upon.

Restoration of Biology is essentially the core principle of Regenerative medicine. Regenerative Medicine is defined as "Regenerative Medicine is an emerging interdisciplinary field of research and clinical applications focused on the repair, replacement or regeneration of cells, tissues or organs to restore impaired function resulting from any cause, including congenital defects, disease, trauma and aging." [1]. From the definition is clear the optimal restoration of functional biology is the aim of Regenerative medicine as opposed to clinical medicine where most of the focus lies on treating the symptoms or the external causative factors

Regenerative medicine is a multidisciplinary branch which includes principles from engineering as well as biological sciences to utilise the innate ability of body to heal itself. A major part of this branch is dedicated to harvesting this ability while other parts are focussed on enhancing this ability or even replacing this ability by artificial means. The fact that earliest use of regenerative medicine was in early 1900 to prolong life or more specifically to slow the aging process. Although the term Regenerative medicine was coined in 1992 it was made popular only in 1999 and has seen the attention as well as applications in the field grow exponentially since then [2].

The scope of regenerative medicine is ever expanding but broadly focussed on tissue engineering and tissue regeneration [3]. The Journal of Regenerative Science will focus more on tissue regeneration part, although advances and research in tissue engineering will receive special attention. When talks about this journal started few months back with Dr Daniel Moya, we were talking mostly in terms of tissue regeneration specifically non-invasive tissue regeneration using shockwaves. We had together conducted special webinars and scheduled talk on Shockwave therapies on our portal OrthoTV where we go incredible response to the concept. Feedback from viewers and especially orthopaedic surgeons was fantastic. We realised that this specific branch of regenerative medicine can be utilised quite effectively in musculoskeletal areas and would create a lot of positive impact on patient outcomes too. From this realisation stemmed the idea of creating a dedicated academic platform in form of Journal of Regenerative Science. It took us time to solidify the idea and find people who are as passionate as us about the subject. It is our great privilege to introduce the Editorial board of the Journal with the launch of first issue of JRS. We planned the first issue in two months and thanks to great effort by every author, we were able to bring out the first issue is a very short time. The issue is an excellent collection of invited articles form experts from across the globe and we are sure that reader will find value in reading these articles

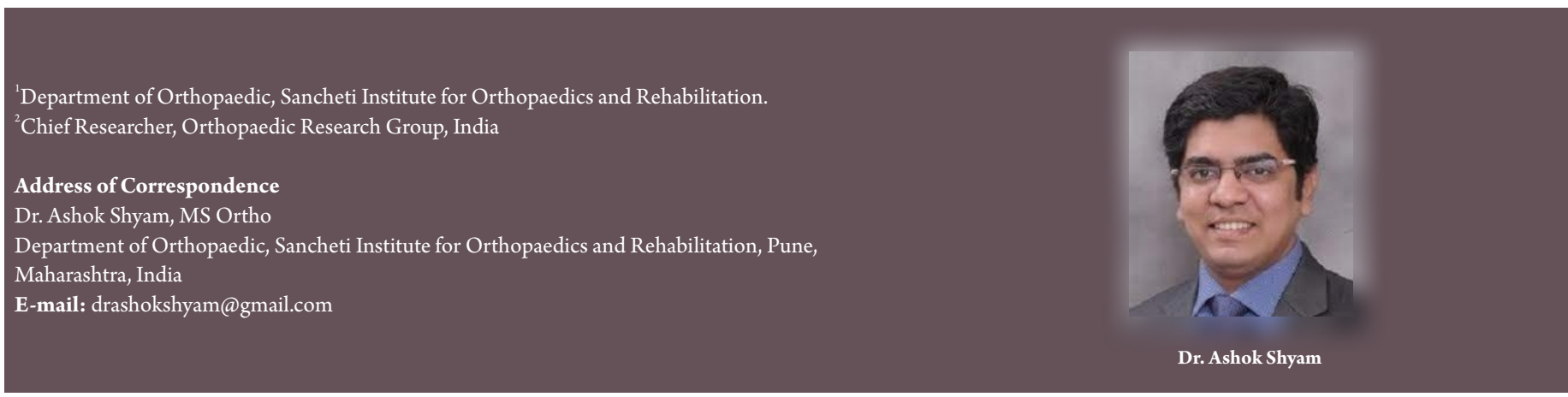

(C) 2021 by Journal of Regenerative Science | Available on www.jrsonweb.com | DOI:10.13107/jrs.2021.v01.i01.001

This is an open access journal, and articles are distributed under the terms of the Creative Commons Attribution-NonCommercial-ShareAlike 4.0 License (https://creativecommons.org/licenses/by-nc-sa/4.0/), which allows others to remix, tweak, and build upon the work non-commercially, as long as appropriate credit is given and the new creations are licensed under the identical terms. 
Regenerative science is a very futuristic branch, and it is still in its development phase. This is the stage where both the branch and the practitioner of the branch need to support each other through good research. For any new branch, current research is the foundation on which the future will be decided on. JRS is aimed to provide a peer reviewed platform where researchers can publish their research and help in growth of the speciality. JRS editorial board and reviewers list consists of great experts in the field and more will be joining us. This will help in maintaining highest quality of articles and publication in the Journal. At the same time, we wish to keep the focus of the articles to practical patient care too. Keeping both the academic as well as clinical aspect in mind we would like to extend an open invitation to all researchers in the field of Regenerative science to submit their work to the Journal

The first issue is in your hands, and it is a work of lot of Love and hard work form authors and the editorial team. We sincerely hope that you will enjoy reading the articles and send us your feedback

Wishing you a Very Safe and Happy New Year

\section{References}

1. Mason C, Dunnill P. A brief definition of regenerative medicine. Regen Med. 2008 Jan;3(1):1-5.

2. Sampogna G, Guraya SY, Forgione A.

Regenerative medicine: Historical roots and potential strategies in modern medicine. J Microsc Ultrastruct. 2015 Jul-Sep;3(3):101-107

3. Mao AS, Mooney DJ. Regenerative medicine: Current therapies and future directions. Proc Natl Acad Sci U S A. 2015;112(47):14452-14459.

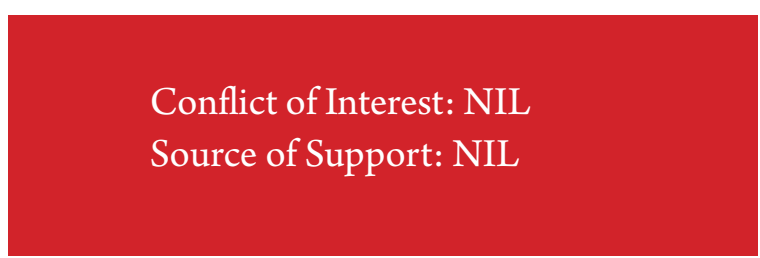

How to Cite this Article

Shyam A. Journal of Regenerative Science: A Step towards a more Biological Future | Journal of Regenerative Science | December 2021; 1(1): 1-2. 